\title{
Identification of microRNAs in response to aluminum stress in the roots of Tibetan wild barley and cultivated barley
}

\author{
Liyuan Wu, Jiahua Yu, Qiufang Shen, Lu Huang, Dezhi Wu* and Guoping Zhang
}

\begin{abstract}
Background: Barley is relatively sensitive to Aluminum (Al) toxicity among cereal crops, but shows a wide genotypic difference in Al tolerance. The well-known Al-tolerant mechanism in barley is related to Al exclusion mediated by a citrate transporter HvAACT1 (Al-activated citrate transporter 1). A 1-kb insertion in the promoter region of HVAACT1 gene results in a dramatic increase of its expression level, which only occurs in some Al-tolerant cultivars. However, Al-tolerant Tibetan wild barley accession XZ29 did not have the 1-kb insertion.

Results: We confirmed that the expression of HVAACT1 and secretion of citrate and other organic acids did not explain the difference in Al-tolerant wild barley XZ29 and Al-sensitive cultivated barley Golden Promise. To identify microRNAs (miRNAs) and their target genes responsive to Al stress in barley roots, eight small RNA libraries with two biological replicates from these two genotypes exposed to control and Al-treated conditions were constructed and submitted to deep sequencing. A total of 342 miRNAs were identified in Golden Promise and XZ29, with 296 miRNAs being commonly shared in the two genotypes. Target genes of these miRNAs were obtained through bioinformatics prediction or degradome identification. Comparative analysis detected 50 miRNAs responsive to Al stress, and some of them were found to be exclusively expressed in XZ29 and associated with Al tolerance.
\end{abstract}

Conclusions: miRNAs exclusively expressing in the wild barley were identified and found to be associated with Al stress tolerance. The current results provide a model of describing the roles of some special miRNAs associated with Al tolerance in the Tibetan wild barley.

Keywords: Tibetan wild barley, Aluminum resistance, miRNA, Small RNA sequencing, Root growth, Target genes

\section{Background}

Aluminum (Al) is a most abundant metal in the Earth's crust. Although $\mathrm{Al}$ is nontoxic in the form of aluminosilicate minerals, toxicity arises when $\mathrm{Al}$ ions $\left(\mathrm{Al}^{3+}\right)$ are solubilized from minerals and released into soils with the $\mathrm{pH}$ values below 5 [1]. It has been estimated that as much as approximately $50 \%$ of potentially arable lands in the world are acidic [2]. Al ions severely inhibit root growth and reduce the uptake of water and nutrients, thus finally reducing crop yields in acid soils [3].

To detoxify Al, some Al-tolerant plants have developed a variety of external and internal Al tolerant mechanisms. The external $\mathrm{Al}$ exclusion strategy is achieved by

\footnotetext{
* Correspondence: wudezhi@zju.edu.cn

Department of Agronomy, College of Agriculture and Biotechnology, Zhejiang University, Hangzhou 310058, China
}

release of organic acids anions, such as citrate, malate and oxalate, from roots into rhizosphere to chelate $\mathrm{Al}$ [4-6]. Genes responsible for Al-induced citrate and malate release have been identified, which are members of MATE (multidrug and toxic compound extrusion) or ALMT (Al-activated malate transporter) families [7-9].

Unlike the external $\mathrm{Al}$ exclusion, the internal tolerance mechanisms are achieved by modification of root cell wall and subsequent sequestration of absorbed $\mathrm{Al}$ into vacuoles [10]. Plant root cell wall is the first barrier for $\mathrm{Al}$ getting into cells, where more than $90 \% \mathrm{Al}$ is bound [11]. As one of the important components in cell wall, pectin exists in highly methylated form, but can transform into negatively charged demethylation type by pectin methylesterases (PMEs), leading to more $\mathrm{Al}$ ions binding [12]. Al sensitive rice genotype exhibited a higher PME activity and demethylated pectin proportion [13]. Furthermore, the

(c) The Author(s). 2018 Open Access This article is distributed under the terms of the Creative Commons Attribution 4.0 International License (http://creativecommons.org/licenses/by/4.0/), which permits unrestricted use, distribution, and 
lines with OsPME14 overexpression accumulated more $\mathrm{Al}$ in root tip cell wall and showed more sensitivity to $\mathrm{Al}$ stress [14]. In addition, an ABC (ATP-binding cassette) transporter complex formed by OsSTAR1 (sensitive to Al rhizotoxicity) and OsSTAR2 proteins is involved specifically in efflux of UDP-glucose, which possibly results in modification of cell wall [15]. To prevent more $\mathrm{Al}$ accumulation in cell wall, plasma membrane localized transporter OsNart1 (Nramp aluminum transporter 1) removes $\mathrm{Al}$ specifically from root cell wall into cytosol, and then sequesters $\mathrm{Al}$ into vacuoles with the help of tonoplast localized ABC transporter OsALS1 (Al-sensitive 1 ) in rice $[16,17]$. Unlike the most plants accumulating $\mathrm{Al}$ in roots, some species such as hydrangea and buckwheat alleviate $\mathrm{Al}$ damage by translocating $\mathrm{Al}$ from roots to shoots in nontoxic forms $[18,19]$. In hydrangea sepal tissue, two aquaporin family members HmPALT1 (plasma membrane aluminum transporter 1) and HmVALT (vacuolar aluminum transporter) were identified as $\mathrm{Al}$ transporters, which play important role in $\mathrm{Al}$ tolerance [20,21]. In addition to the genes mentioned above, some transcription factors have also been identified in Al-induced pathways. OsART1 (Al resistance transcription factor 1) is quite important in $\mathrm{Al}$ tolerance, because it regulates at least 31 genes to detoxify $\mathrm{Al}$, such as OsSTAR1, OsSTAR2, OsNrat1 and so on [15, 16, 22].

Barley is considered as one of the most $\mathrm{Al}$-sensitive cereal crops and also shows a wide genotypic difference in $\mathrm{Al}$ tolerance, such as Al-sensitive cultivar Golden Promise and Al-tolerant cultivar Dayton [23, 24]. The well-known tolerant mechanism in barley is related to $\mathrm{Al}$ exclusion mediated by citrate transporter HvAACT1 [8]. It was reported that $1-\mathrm{kb}$ insertion in upstream of $H v A A C T 1$ coding sequence could greatly enhance its expression level, resulting in more citrate secretion to chelate $\mathrm{Al}$ and higher $\mathrm{Al}$ tolerance, as reflected by Al-tolerant cultivars such as Dayton [23, 24]. While the 1 -kb insertion was not found in the Al-sensitive cultivars, such as Golden Promise, in our previous study, $1-\mathrm{kb}$ insertion was not observed in an Al-tolerant Tibetan wild barley accession XZ29, which did not secret more citrate and other organic acids under $\mathrm{Al}$ stress $[23,24]$. On the other hand, GWAS analysis detected two novel loci associated with $\mathrm{Al}$ tolerance in the $\mathrm{Ti}$ betan wild barley, but not in cultivars [25]. Tibetan wild barley, inhabited in Tibet plateau with extremely harsh environment which is considered as one of the centers of cultivated barley domestication, is rich in genetic diversity of abiotic stress tolerance [26]. Therefore, it may be assumed that other mechanisms different from the known $\mathrm{Al}$ exclusion in cultivated barley might exist in Tibetan wild barley in $\mathrm{Al}$ tolerance.

Recently, more and more researches have been done to study gene regulation mediated by miRNAs, which bind with target mRNAs through complementary base pairing, leading cleavage to target genes [27]. MicroRNAs are a kind of noncoding small RNAs with the length of 20-24 nucleotides, they play critical roles in many aspects of plant development, metabolism and biotic and abiotic stress responses [27, 28]. Among them, the family of miRNA156 is highly conserved and regulates SPL (Squamosa Promoter Binding-Like) target genes associated with plant architecture and tuber yield in potato, panicle branching, grain quality and some other traits in rice [29-31]. In addition to development processes, some miRNAs are also involved in stress resistance. For example, microRNA390 could be responsive to heavy metals stress, including $\mathrm{Cd}$ and $\mathrm{Al}$ toxicity $[32,33]$. Thus it is interesting to determine whether $\mathrm{Al}$ tolerance in Tibetan wild barley is involved in the special miRNAs and the possible difference in the miRNA associated with $\mathrm{Al}$ tolerance between the wild and cultivated barley.

To understand the possible roles that miRNAs and their potential target genes play in Al-tolerant regulatory networks, small RNA libraries from roots of Tibetan wild barley XZ29 and cultivated barley Golden Promise exposed to $\mathrm{Al}$ stress and control (without $\mathrm{Al}$ treatment) were constructed and submitted to deep sequencing by high-throughput sequencing technology. In addition to the miRNAs reported previously, a number of novel miRNAs were validated in these libraries, which greatly enriches barley microRNA data. Furthermore, analysis of miRNAs and their target genes in response to $\mathrm{Al}$ stress provide a new insight into understanding of Al-tolerant mechanism in barley, especially Tibetan wild barley.

\section{Results}

\section{The difference in Al tolerance between Golden Promise} and XZ29

Under normal condition without $\mathrm{Al}$ stress, three genotypes showed much similar root growth and length (Fig. 1a, Additional file 1: Figure S1). After 9 days of $\mathrm{Al}$ treatment, the longest root elongation was inhibited more in Golden Promise than in XZ29 and Dayton under the two $\mathrm{Al}$ concentrations (5 and $10 \mu \mathrm{M}$ ) (Fig. 1a, b, c, Additional file 1: Figure S1). The relative root elongation was suppressed less in XZ29 than in Dayton at $10 \mu \mathrm{M} \mathrm{Al}$, although the similar inhibition was found for the two genotypes at $5 \mu \mathrm{M} \mathrm{Al}$ (Fig. 1d).

Root $\mathrm{Al}$ concentration increased with external $\mathrm{Al}$ level for Golden Promise and XZ29 (Fig. 1d), but for Dayton, there was no obvious difference in root $\mathrm{Al}$ concentration between 5 and $10 \mu \mathrm{M} \mathrm{Al}$ treatments. Moreover, XZ29 showed lower root $\mathrm{Al}$ concentration than Golden Promise at either $5 \mu \mathrm{M}$ or $10 \mu \mathrm{M}$ Al. By contrast, root $\mathrm{Al}$ concentration was much higher in XZ29 than in Dayton at $10 \mu \mathrm{M} \mathrm{Al}$. These results confirmed again that Al-tolerant 

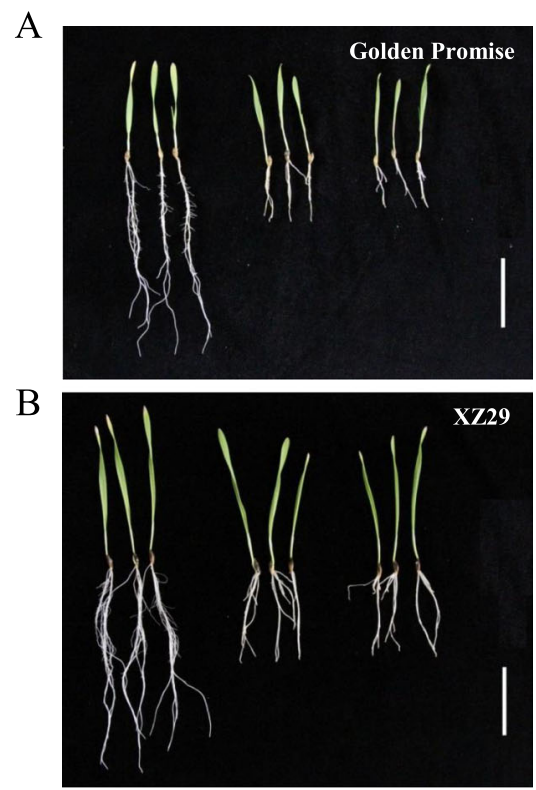

$\mathrm{C}$

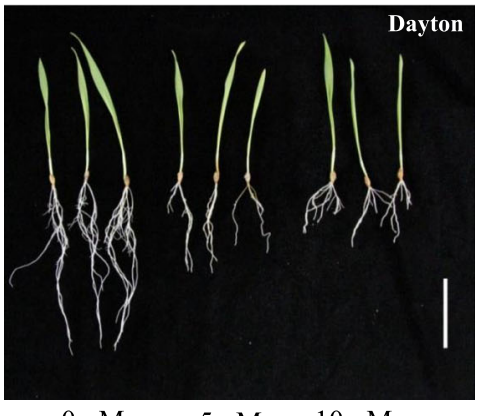

$0 \mu \mathrm{M} \quad 5 \mu \mathrm{M} \quad 10 \mu \mathrm{M}$
$\mathrm{D}$
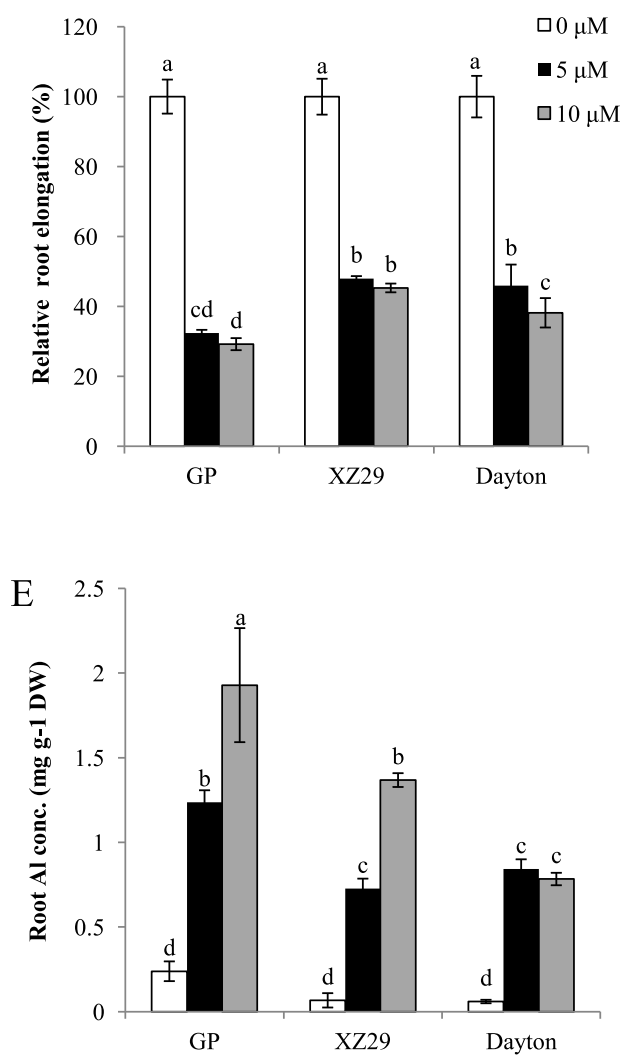

Fig. 1 The difference in Al tolerance among three barley genotypes. a-c, Growth of Golden Promise (GP) (a),XZ29 (b) and Dayton (c) at different Al concentration. Three-day-old seedlings were exposed to Al for 9 days. Relative root elongation (d) and the whole root Al concentration (e) in three genotypes. Data are means \pm SD of six and three biological replicates for $\mathbf{d}$ and $\mathbf{e}$ respectively, and means labeled with different letters are significantly different at $p<0.05$ by Tukey' test

genotype XZ29 had lower root $\mathrm{Al}$ concentration than $\mathrm{Al}-$ sensitive cultivar Golden Promise.

The difference in 1-kb insertion, HvAACT1 expression level and organic acids secretion between Golden Promise and XZ29

To understand whether HvAACT1 is responsible for the difference of Al tolerance between XZ29 and Golden Promise, 1-kb insertion, HvAACT1 expression level and organic acids secretion were analyzed. The results showed that both Golden Promise and XZ29 had no 1-kb insertion and much lower HvAACT1 expression level and less citrate secretion in comparison with Dayton which had 1-kb insertion (Fig. 2a, b, c). In addition, there was no significant difference in malate and oxalate secretion among these three genotypes (Fig. 2d). Obviously citrate secretion, which is associated with 1-kb insertion and high $\mathrm{Al}$ tolerance for Dayton, cannot explain the $\mathrm{Al}$ stress tolerance for XZ29.
The difference in small RNA deep sequencing between Golden Promise and XZ29

To identify the miRNAs in response to $\mathrm{Al}$ stress, eight small RNA libraries were constructed from roots of Golden Promise and XZ29 in control and Al-treated conditions. Totally 11,574,070, 11,798,931, 11,004,065 and $12,720,633$ raw reads were generated by high-throughput sequencing respectively for two genotypes and two treatments (Table 1). After a series data processing, including filtration of small RNAs except miRNAs, $5,487,588,5,379,474,5,608,740$ and $4,495,143$ total valid reads, corresponding to $1,464,860,2,086,577,1,850,953$ and 1,346,101 unique reads were acquired in the libraries of Golden Promise in control and Al treatment, XZ29 in control and Al treatment, respectively. The majority of valid reads were in length of 19-24 nt, with 24 nt reads being most dominant for Golden Promise after Al treatment, which occupied $27.4 \%$ total reads (Additional file 2: Figure S2). 


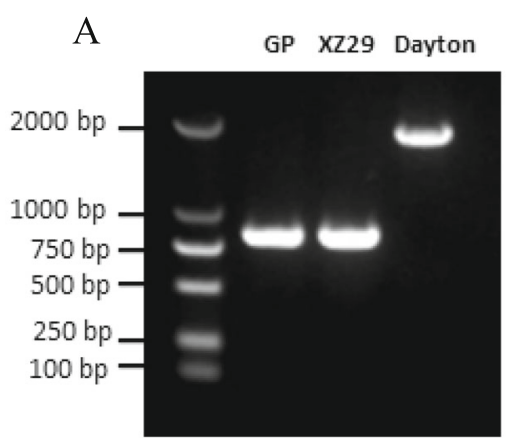

C

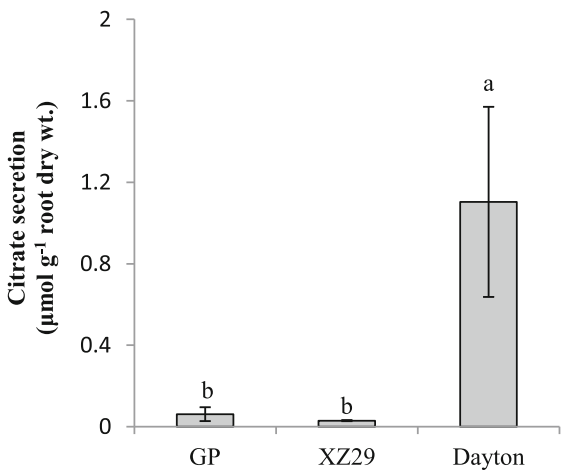

B

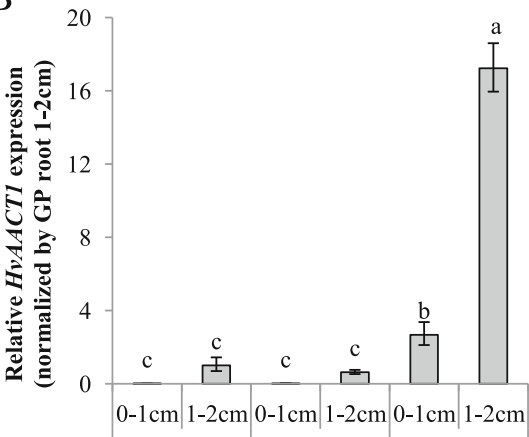

GP

Dayton

$\mathrm{D}$

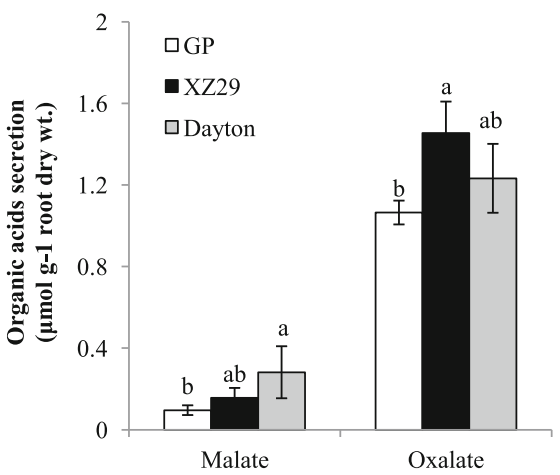

Fig. 2 The difference in 1-kb insertion, HVAACT1 expression and organic acids secretion among three barley genotypes. a Detection of 1-kb insertion in the upstream of HVAACT1 coding region. $\mathbf{b}$ Expression level of HVAACT1. Two root segments $(0-1 \mathrm{~cm}$ and $1-2 \mathrm{~cm}$ from tips) from fourday-old seedlings were sampled after exposure to $10 \mu \mathrm{M} \mathrm{Al}$ for $6 \mathrm{~h}$. Actin was used as an internal control and expression relative to 1-2 $\mathrm{cm}$ root segments of Golden Promise (GP) is shown. Al-induced citrate (c), malate and oxalate (d) secretion. Root exudates were collected after four-dayold seedlings were exposed to $10 \mu \mathrm{M}$ Al for $6 \mathrm{~h}$. Data in $\mathbf{b}, \mathbf{c}$ and $\mathbf{d}$ are means \pm SD of three biological replicates and means labeled with different letters are significantly different at $p<0.05$ by Tukey' test

Identification of the miRNAs expressing in the two barley genotypes under different Al treatments

All valid reads from eight small RNA libraries were blasted to miRBase (release 21), which is composed of 35,828 mature miRNAs from 223 species including 72 plant species. A total of 342 miRNAs were identified in the roots of Golden Promise and XZ29, of which 296 miRNAs were shared by the two genotypes (Fig. 3a,
Additional file 3: Table S1). All these miRNAs could be divided into three classes, i.e. known miRNAs, new members of known miRNAs and potentially candidate miRNAs, respectively. Known miRNAs included 116 members, perfectly or near perfectly matching to mature miRNAs from barley or other plant species (two mismatches were allowed). New members of known miRNAs included 51 miRNAs, and no mature miRNAs in

Table 1 The profiles of small RNA deep sequencing for the two barley genotypes under different Al treatments

\begin{tabular}{|c|c|c|c|c|c|c|c|c|}
\hline \multirow[t]{2}{*}{ Library type } & \multicolumn{2}{|c|}{ Golden Promise-Control } & \multicolumn{2}{|c|}{ Golden Promise-Al } & \multicolumn{2}{|c|}{ XZ29-control } & \multicolumn{2}{|l|}{ XZ29-Al } \\
\hline & Total reads & Unique reads & Total reads & Unique reads & Total reads & Unique reads & Total reads & Unique reads \\
\hline Raw reads & $11,574,070$ & $2,543,454$ & $11,798,931$ & $3,336,429$ & $11,004,065$ & $2,783,930$ & $12,720,633$ & $2,389,395$ \\
\hline Cut adapter and length filter & $3,207,755$ & 967,414 & 2,299,195 & $1,121,113$ & $2,424,530$ & 830,285 & $2,849,733$ & 908,411 \\
\hline Junk reads & 120,196 & 23,277 & 113,489 & 34,527 & 96,376 & 25,693 & 132,744 & 20,175 \\
\hline Rfam & $1,164,361$ & 37,372 & $1,586,198$ & 41,593 & $1,177,236$ & 34,644 & $2,698,268$ & 38,246 \\
\hline mRNA & $2,052,214$ & 61,746 & $3,482,187$ & 65,806 & $2,162,010$ & 53,694 & $3,360,733$ & 90,151 \\
\hline Repeats & 18,200 & 713 & 11,739 & 342 & 15,180 & 543 & 49,047 & 848 \\
\hline valid reads & $5,487,588$ & $1,464,860$ & $5,379,474$ & $2,086,577$ & $5,608,740$ & $1,850,953$ & $4,495,143$ & $1,346,101$ \\
\hline
\end{tabular}




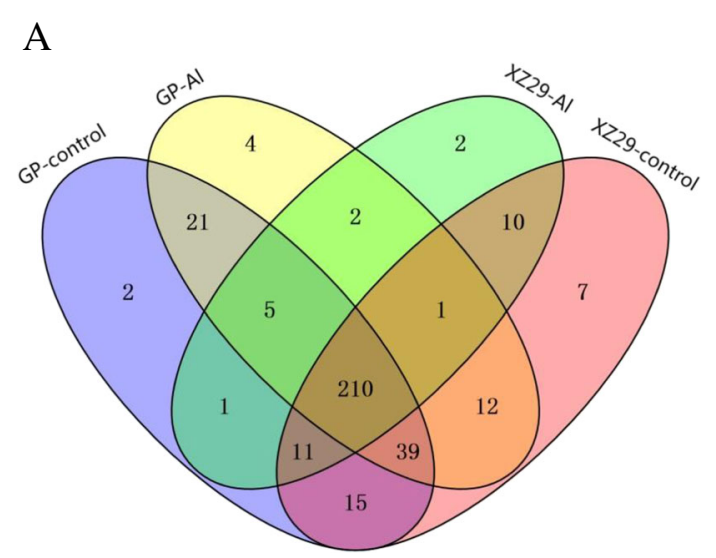

B

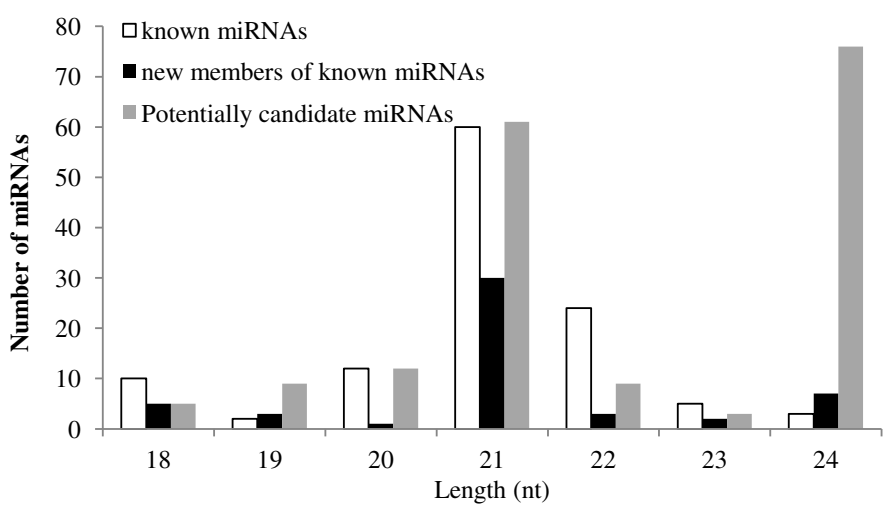

Fig. 3 The identified miRNAs from roots of Golden Promise (GP) and XZ29. a Number of miRNAs in control and Al-treated roots of two genotypes. $\mathbf{b}$ Length distribution of total identified miRNAs. A total of 342 miRNAs were found. They were divided into three classes: known miRNAs, new members of known miRNAs and potentially candidate miRNAs

miRBase were matched to them, but they corresponded to one strand of precursors. There were 175 potentially candidate miRNAs to which no matter mature miRNAs or precursors could match. They were generally at low expression level. Length distribution of these three classes of miRNAs showed that $21 \mathrm{nt}$ sequences were the most abundant in known miRNAs and new members of known miRNAs, while 24 nt sequences were dominant in potentially candidate miRNAs (Fig. 3b).

\section{Function analysis of miRNA targets in barley}

Putative targets for 178 miRNAs were identified while for numerous potentially candidate miRNAs targets were not found (Additional file 3: Table S1). Among 178 miRNAs, 103 miRNAs were predictably associated with 136 target genes, and based on degradome analysis, the rest $75 \mathrm{miR}$ NAs regulated other 136 target genes. Many target genes are transcription factors, indicating showing that miRNAs play important roles in regulatory networks. For example, $S P L$ transcription factor 2 and 3 were negatively regulated by ata-miR156a-5p, ARFs (auxin response factors) was antagonized by ata-miR160a-5p, NAC (NAM, ATAF1/2 and CUC2) transcription factors were dampened by miR164 family members.

\section{Identification of miRNAs responsive to Al stress}

A total of 50 highly expressed miRNAs in XZ29 and Golden Promise were responsive to $\mathrm{Al}$ stress (Table 2). Among them, 17 miRNAs were up-regulated, 24 miRNAs were down-regulated and 8 miRNAs remained unchanged in XZ29. However, 29 miRNAs were responsive to $\mathrm{Al}$ in Golden Promise. These miRNAs included known miRNAs such as ata-miR156a-5p and hvu-miR166a, new members of known miRNAs such as hvu-MIR159a-p5 and ata-MIR169d-3p and potentially candidate miRNAs, such as PC-miR1, PC-miR2, PC-miR4 and PC-miR6. Potentially candidate miRNAs PC-miR1 and PC-miR2 were only expressed in XZ29 while PC-miR4 was specifically expressed in Golden Promise. Degradome analysis demonstrated that 24 miRNAs, including ata-miR160a-5p, osa-miR319a-3p.2-3p, ata-miR393-5p, ata-miR396a-5p and ata-miR396e-5p were associated with 46 target genes, including auxin response factors, TCP family transcription factor 4, HvAFB/HVTIR1 and growth-regulating factors (Table 2).

\section{Transcript analysis of miRNA target genes}

According to gene annotations, putative targets for 50 miRNAs were associated with a variety of biological processes such as auxin responses, growth regulation and so on (Table 2). Four target genes from $\mathrm{Al}$ responsive miRNAs were randomly selected for qRT-PCR analysis to confirm reads of high-throughput sequencing and accuracy of target gene identification. The expression level of osa-miR319a-3p.2-3p was significantly up-regulated and target gene HORVU1Hr1G094160.1 (TCP4) was down-regulated in XZ29, however there was no obvious difference for the expression of osa-miR319a-3p.2-3p and its target gene in Golden Promise (Fig. 4a). osa-miR444a-3p.2 was down-regulated in XZ29 and little changed in Golden Promise, while the target gene HORVU2Hr1G08490.1 (MADS27) was up regulated by 2.2- and 2.0-fold in XZ29 and Golden Promise, respectively (Fig. 4b). The expression of ata-miR1432-5p was significantly down-regulated and its target gene HORVU1Hr1G094160.1 (CML43) was up-regulated in Golden Promise, while XZ29 showed little change in the expression of both ata-miR1432-5p and its target gene (Fig. 4c). As shown in Fig. 4d, ath-miR8175 was up-regulated in XZ29 and down-regulated in Golden Promise. The target gene HORVU5Hr1G085710.3 
Table 2 miRNAs in response to Al stress

\begin{tabular}{|c|c|c|c|c|c|}
\hline miRNA name & $G P^{a}$ & $X Z 29^{b}$ & Transcript & Annotation & $\begin{array}{l}\text { Degradome } \\
\text { detection }^{c}\end{array}$ \\
\hline ata-miR156a-3p & 0.20 & 0.89 & HORVU3Hr1G072810.1 & Gibberellin 2-oxidase & Y \\
\hline \multirow[t]{2}{*}{ ata-miR156a-5p } & -0.49 & 0.91 & HORVU3Hr1G094730.2 & Squamosa promoter-binding-like protein 2 & Y \\
\hline & & & HORVU6Hr1G019700.2 & Squamosa promoter-binding-like protein 3 & Y \\
\hline \multirow[t]{2}{*}{ bdi-miR156h-3p } & 0.33 & -1.15 & HORVU4Hr1G025850.7 & Structure-specific endonuclease subunit slx 1 & N \\
\hline & & & HORVU4Hr1G012480.3 & Leucine-rich receptor-like protein kinase family protein & N \\
\hline hvu-miR159a & -0.21 & -0.67 & HORVU3Hr1G079490.4 & MYB domain protein 33 & Y \\
\hline hvu-MIR159a-5p & -0.44 & -1.36 & HORVU1Hr1G088510.1 & Mitogen-activated protein kinase 16 & $\mathrm{~N}$ \\
\hline \multirow[t]{2}{*}{ osa-miR319a-3p.2-3p } & -0.35 & 0.76 & HORVU5Hr1G103400.1 & TCP family transcription factor 4 & Y \\
\hline & & & HORVU2Hr1G060120.1 & TCP family transcription factor 4 & Y \\
\hline \multirow[t]{4}{*}{ ata-miR160a-5p } & -0.44 & -0.77 & HORVU2Hr1G089670.2 & Auxin response factor 10 & Y \\
\hline & & & HORVU7Hr1G101270.6 & Auxin response factor 16 & Y \\
\hline & & & HORVU6Hr1G026750.1 & Auxin response factor 18 & Y \\
\hline & & & HORVU1Hr1G041770.6 & Auxin response factor 22 & Y \\
\hline ata-miR164c-3p & 0.37 & 0.63 & HORVU6Hr1G088160.5 & Quinone oxidoreductase & Y \\
\hline \multirow[t]{4}{*}{ hvu-miR166a } & -0.82 & -1.61 & HORVU5Hr1G010650.1 & Homeobox-leucine zipper protein family & Y \\
\hline & & & HORVU5Hr1G061410.29 & Homeobox-leucine zipper protein HOX10 & Y \\
\hline & & & HORVU0Hr1G010250.3 & Homeobox-leucine zipper protein HOX32 & Y \\
\hline & & & HORVU1Hr1G041790.2 & Homeobox-leucine zipper protein family & Y \\
\hline ata-miR166a-3p & -0.54 & -1.84 & HORVUOHr1G010250.3 & Homeobox-leucine zipper protein HOX32 & N \\
\hline ata-miR166a-5p & -0.71 & -0.03 & HORVU5Hr1G056820.4 & Histidine protein methyltransferase 1 homolog & N \\
\hline ata-miR166d-5p & -0.53 & -0.29 & HORVU4Hr1G018020.2 & F-box/WD-40 repeat-containing protein & N \\
\hline ata-miR167a-5p & -0.63 & -0.17 & HORVU2Hr1G121110.32 & Auxin response factor 6 & Y \\
\hline ata-miR167b-3p & -0.92 & -0.71 & HORVU1Hr1G075520.2 & Jacalin-related lectin 3 & N \\
\hline ata-miR167b-5p & 0.58 & -0.23 & HORVU2Hr1G059280.1 & SWI/SNF complex subunit SWI3C & $N$ \\
\hline \multirow[t]{2}{*}{ tae-miR167c-5p } & 0.64 & -2.00 & HORVU1Hr1G077630.2 & Ubiquitin carboxyl-terminal hydrolase 25 & N \\
\hline & & & HORVU2Hr1G059280.1 & SWI/SNF complex subunit SWI3C & N \\
\hline ata-miR167f-3p & 0.29 & 0.84 & HORVU4Hr1G016990.3 & Cysteine desulfurase & N \\
\hline hvu-miR168-3p & -0.71 & 1.04 & HORVU5Hr1G037570.4 & Receptor-like protein kinase & N \\
\hline hvu-miR168-5p & -0.55 & -0.83 & HORVU1Hr1G055570.4 & WD repeat-containing protein WRAP73 & Y \\
\hline \multirow[t]{3}{*}{ ata-miR169i-5p } & 0.42 & -1.58 & HORVU5Hr1G092700.17 & Nuclear transcription factor $Y$ subunit A-10 & Y \\
\hline & & & HORVU4Hr1G075830.4 & Nuclear transcription factor Y subunit A-3 & Y \\
\hline & & & HORVU6Hr1G081080.12 & Nuclear transcription factor $Y$ subunit A-5 & Y \\
\hline \multirow[t]{3}{*}{ ata-miR169d-5p } & -0.46 & -0.86 & HORVU5Hr1G092700.17 & Nuclear transcription factor $Y$ subunit A-10 & Y \\
\hline & & & HORVU4Hr1G075830.4 & Nuclear transcription factor Y subunit A-3 & Y \\
\hline & & & HORVU6Hr1G081080.12 & Nuclear transcription factor Y subunit A-5 & Y \\
\hline ata-MIR169d-3p & -0.91 & -1.82 & HORVU5Hr1G089950.4 & Chromodomain-helicase-DNA-binding protein Mi-2 homolog & $\mathrm{N}$ \\
\hline ata-miR169h-3p & -0.81 & 0.18 & HORVU1Hr1G075540.3 & Mitochondrial processing peptidase alpha subunit & Y \\
\hline ata-miR171b-5p & -0.70 & 0.14 & HORVU5Hr1G081160.4 & U-box domain-containing protein 73 & N \\
\hline ata-miR171a-5p & -1.42 & -1.15 & HORVU2Hr1G076620.7 & T-complex protein 11 & Y \\
\hline \multirow[t]{2}{*}{ ata-miR172b-3p } & -0.63 & -0.55 & HORVU5Hr1G112440.1 & Ethylene-responsive transcription factor 10 & Y \\
\hline & & & HORVU1Hr1G011800.24 & AP2-like ethylene-responsive transcription factor & Y \\
\hline ata-miR390-5p & -1.86 & -0.56 & HORVU7Hr1G007520.1 & Leucine-rich repeat receptor-like protein kinase family protein & N \\
\hline
\end{tabular}


Table 2 miRNAs in response to Al stress (Continued)

\begin{tabular}{|c|c|c|c|c|c|}
\hline miRNA name & $G P^{a}$ & $X Z 29^{b}$ & Transcript & Annotation & $\begin{array}{l}\text { Degradome } \\
\text { detection }^{c}\end{array}$ \\
\hline \multirow[t]{2}{*}{ ata-miR393-5p } & -0.16 & -1.57 & HORVU2Hr1G070800.3 & HvAFB & Y \\
\hline & & & HORVU1Hr1G021550.4 & HVTIR1 & Y \\
\hline \multirow[t]{2}{*}{ ata-miR394-5p } & -1.18 & -0.30 & HORVU1Hr1G043940.3 & Protein TIC110, chloroplastic & $\mathrm{N}$ \\
\hline & & & HORVU6Hr1G018370.1 & Calnexin 1 & $\mathrm{~N}$ \\
\hline \multirow[t]{3}{*}{ ata-miR396a-5p } & 0.16 & -1.20 & HORVU7Hr1G008680.14 & Growth-regulating factor 5 & Y \\
\hline & & & HORVU4Hr1G010080.6 & Growth-regulating factor 6 & Y \\
\hline & & & HORVU4Hr1G003440.12 & Growth-regulating factor 9 & Y \\
\hline \multirow[t]{3}{*}{ ata-miR396e-5p } & 0.51 & -1.46 & HORVU7Hr1G008680.14 & Growth-regulating factor 5 & Y \\
\hline & & & HORVU4Hr1G010080.6 & Growth-regulating factor 6 & Y \\
\hline & & & HORVU4Hr1G003440.12 & Growth-regulating factor 9 & Y \\
\hline osa-miR444a-3p.2 & -0.14 & -0.82 & HORVU2Hr1G080490.1 & MADS-box transcription factor 27 & Y \\
\hline ppt-miR477h & 1.34 & 2.83 & HORVU1Hr1G050450.2 & Replication factor $C$ subunit 5 & $\mathrm{~N}$ \\
\hline osa-miR827 & -0.46 & -1.26 & HORVU6Hr1G065710.13 & SPX domain-containing membrane protein & N \\
\hline \multirow[t]{2}{*}{ ata-miR1432-5p } & -1.56 & 0.21 & HORVU1Hr1G094160.1 & Calmodulin like 43 & Y \\
\hline & & & HORVU5Hr1G111520.1 & EF hand calcium-binding protein family & Y \\
\hline \multirow[t]{2}{*}{ hvu-miR5048a } & 0.36 & -1.68 & HORVU7Hr1G065130.1 & Receptor kinase 2 & Y \\
\hline & & & HORVU7Hr1G043150.1 & Protein kinase superfamily protein & Y \\
\hline tae-miR7757-5p & 0.66 & -0.55 & HORVU5Hr1G086040.7 & NBS-LRR disease resistance protein, putative & Y \\
\hline tae-MIR9662a-5p & -0.38 & 2.33 & HORVU5Hr1G123930.2 & Beta-fructofuranosidase, insoluble isoenzyme 3 & $\mathrm{~N}$ \\
\hline \multirow[t]{2}{*}{ ata-MIR9863a-5p } & 0.58 & 1.39 & HORVU5Hr1G007750.22 & FAR1-related sequence 3 & N \\
\hline & & & HORVU1Hr1G004650.4 & Purple acid phosphatase 22 & $\mathrm{~N}$ \\
\hline ppt-miR894 & -0.02 & 2.08 & HORVU7Hr1G041460.1 & $\begin{array}{l}\text { 2-oxoglutarate }(2 \mathrm{OG}) \text { and } \mathrm{Fe}(\mathrm{II}) \text {-dependent } \\
\text { oxygenase superfamily protein }\end{array}$ & Y \\
\hline \multirow[t]{2}{*}{ hvu-miR5051 } & 0.04 & -0.92 & HORVU7Hr1G054660.6 & $\begin{array}{l}\text { Chromosome 3B, genomic scaffold, cultivar } \\
\text { Chinese Spring }\end{array}$ & N \\
\hline & & & HORVU4Hr1G083260.5 & DnaJ homolog subfamily B member 4 & $\mathrm{~N}$ \\
\hline \multirow[t]{2}{*}{ bdi-miR5054 } & -1.98 & 2.07 & HORVU4Hr1G003990.3 & RNA-binding protein 1 & Y \\
\hline & & & HORVU6Hr1G088580.4 & Zinc finger (C3HC4-type RING finger) family protein & Y \\
\hline osa-miR5072 & -1.21 & 1.43 & HORVU3Hr1G075970.2 & Pectate lyase family protein & N \\
\hline \multirow[t]{2}{*}{ gma-miR6300 } & 0.86 & 3.08 & HORVU4Hr1G052010.2 & WRKY DNA-binding protein 46 & Y \\
\hline & & & HORVU0Hr1G035440.1 & Non-specific phospholipase C4 & Y \\
\hline ptc-miR6478 & 1.04 & 3.46 & HORVU7Hr1G076700.1 & Myosin-J heavy chain & N \\
\hline ath-miR8175 & -2.46 & 1.96 & HORVU5Hr1G085710.3 & Aquaporin-like superfamily protein, HvNIP1;2 & N \\
\hline PC-miR1 & 0.00 & -0.73 & HORVU4Hr1G042240.2 & Hexosyltransferase & N \\
\hline PC-miR2 & 0.00 & 1.26 & HORVU1Hr1G074900.1 & BZIP transcription factor & $\mathrm{N}$ \\
\hline PC-miR4 & 2.11 & 0.00 & HORVU6Hr1G035300.19 & U11/U12 small nuclear ribonucleoprotein $25 \mathrm{kDa}$ protein & N \\
\hline PC-miR6 & -0.69 & 0.70 & HORVU6Hr1G076340.1 & Glycosyltransferase family 61 protein & $\mathrm{N}$ \\
\hline
\end{tabular}

${ }^{\mathrm{a}} \mathrm{GP}$ and ${ }^{\mathrm{b}} \mathrm{XZ29}$ represent the fold change between Al treatment and control normalized reads in Golden Promise and XZ29, respectively. It was calculated as the formula: fold change $=\log _{2}$ (Al reads / control reads). miRNAs were significantly up-regulated with fold change $\geq 0.5$, down-regulated with fold change $\leq-0.5$, unchanged with $\mid$ fold change $\mid<0.5$. ${ }^{C}$ Degradome detection shows the target genes of miRNAs. $\mathrm{Y}$ and $\mathrm{N}$ indicate target gene in or not in the degradome sequencing library

$(H v N I P 1 ; 2)$ showed higher expression level in Golden Promise than in XZ29. In short, there was a distinct difference in the expression of some miRNAs as well as their target genes between XZ29 and Golden Promise in responses to $\mathrm{Al}$ stress.

\section{Discussion}

Relative root elongation has been widely used for evaluating $\mathrm{Al}$ tolerance in plants $[15,23]$. In this study, XZ29 was less inhibited in root length and accumulated lower $\mathrm{Al}$ in roots than Golden Promise under $\mathrm{Al}$ 

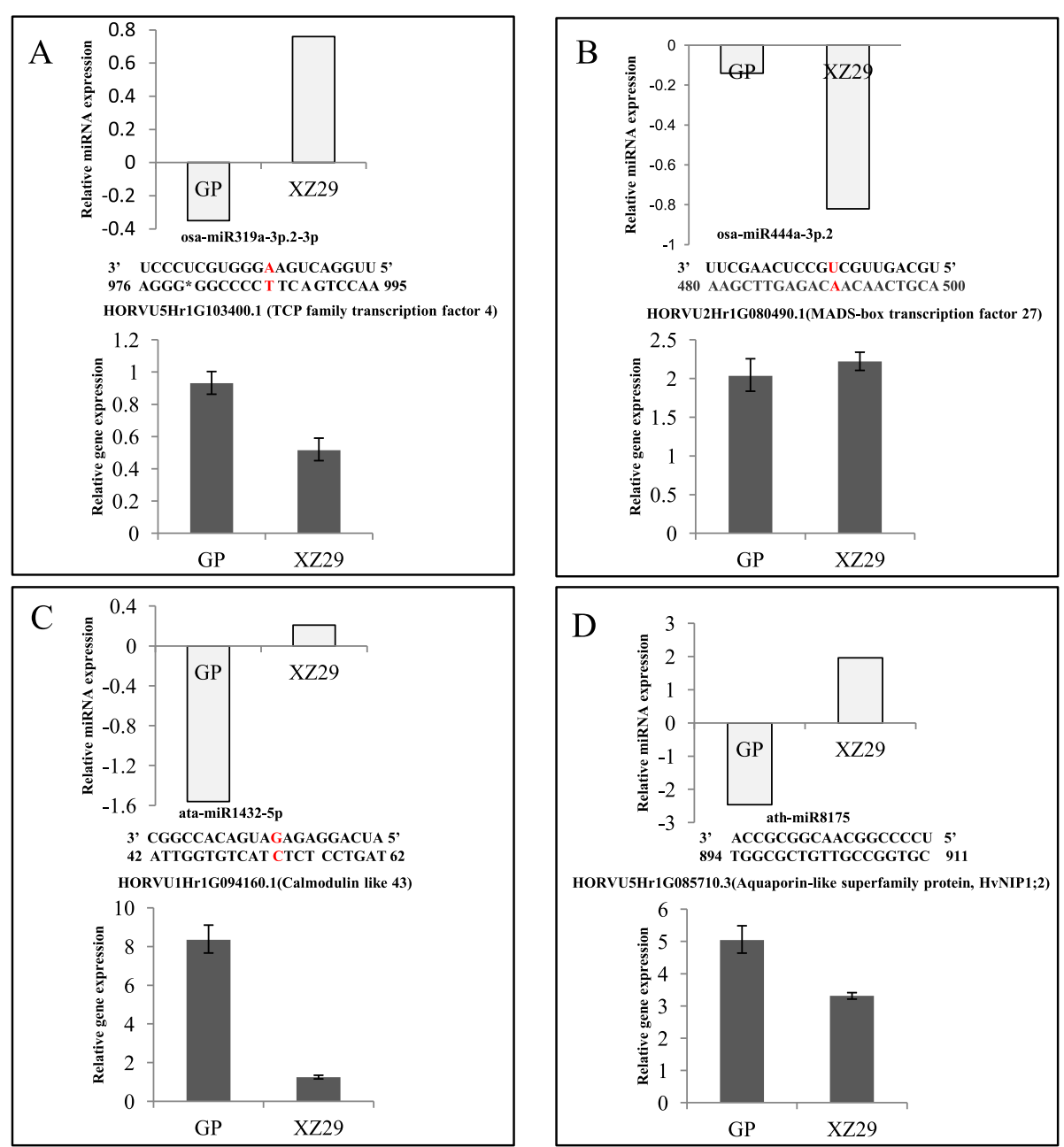

Fig. 4 Expression of miRNAs and their targets in Golden Promise (GP) and XZ29, listed as a osa-miR319a-3p.2-3p, b osa-miR444a-3p.2, c ata-miR1432-5p and $\mathbf{d}$ ath-miR8175. Each panel value of relative miRNA expression represented fold change between Al treatment and control normalized reads from small RNA sequencing. Fold change was calculated as $\log _{2}$ (Al reads/control reads). Data in miRNA expression are means of two biological replicates while in gene expression are means of two biological replicates and two technical replicates. Red letter in sequences indicated miRNA cleavage sites on targets with degradome evidence

stress, proving that XZ29 was higher Al tolerance than Golden Promise (Fig. 1; Additional file 1: Figure S1). Dayton, a well-known Al-tolerant cultivated barley, showed its high Al tolerance through more citrate secretion mediated by citrate transporter HvAACT1, which was attributed to $1-\mathrm{kb}$ insertion in the upstream of HvAACT1 coding region [23, 24]. Such a 1-kb insertion was not detected in Al-sensitive cultivar Golden Promise and Al-tolerant Tibetan wild barley accession XZ29 (Fig. 2a). Furthermore, the expression of HvAACT1 and amount of organic acids including citrate were much lower in XZ29 and Golden Promise than in Dayton (Fig. $2 b-d)$. These results indicated that organic acids efflux from roots into rhizosphere to chelate $\mathrm{Al}$ could not account for Al tolerance in XZ29, and some other mechanisms underlying the $\mathrm{Al}$ tolerant wild barley should exist.
In the past few years, more and more miRNAs have been identified to be associated with biotic or abiotic stress responses in different plant species [27]. In the current study, a total of 342 miRNAs were found in the two barley genotypes XZ29 and Golden Promise, which greatly enriches the database. Based on the comparison of miRNA expression profiles between XZ29 and Golden Promise in control and $\mathrm{Al}$ stress, 50 highly expressed miRNAs responsive to $\mathrm{Al}$ stress were identified and their target genes were also detected through degradome analysis and bioinformatics prediction (Table 2).

\section{Auxin signaling pathway mediated cell wall modification is responsive to $\mathrm{Al}$ stress}

In addition to the direct inhibition of cell elongation, $\mathrm{Al}$ stress also altered ethylene and auxin biosynthesis and 
accumulation in soybean, affecting root growth [34]. miR393 has been found to be associated with various responses to auxin related stress [35, 36]. Hyposensitivity to auxin was observed in miR393 over-expression lines, resulting in the enhanced sensitivity to salt and drought stresses in rice [35]. But in barley, overexpression of miR393 greatly enhanced $\mathrm{Al}$ tolerance through auxin signaling regulation [36]. In the current study, ata-miR393-5p, negatively regulating two auxin receptor genes $H v A F B$ (auxin-signaling F-box) and HVTIR1 (transport inhibitor response), was significantly down-regulated in XZ29, and little changed in Golden Promise under $\mathrm{Al}$ stress. The result was consistent with the report by Bai et al. [36] that the expression of $H v A F B / T I R 1$ was enhanced and their downstream genes $A R F s$ in auxin signaling pathway were also promoted. Consequently, ata-miR160a-5p, the negative regulator of $A R F$ family members, was suppressed much more in XZ29 under $\mathrm{Al}$ stress. Actually it was found that loss-of-function in arf10/16 double Arabidopsis mutant showed higher $\mathrm{Al}$ tolerance due to different expression of genes encoding proteins involved in cell wall modification, including enhanced PMEIs (pectin methylesterase inhibitors), repressed XTH31 (xyloglucan endotransglucosylase/hydrolase) and XTH7 [37]. Therefore, auxin signaling pathway associated with miR160 and miR393 was associated with $\mathrm{Al}$ stress response, which might be a strategy for plants to detoxify Al.

\section{miR319/TCP4 module regulates Al-induced root growth inhibition}

Root length depends on the balance of cell elongation and proliferation. Jasmonic acid and miR396 mediated GRFs (growth-regulating factors) have been reported to be associated with cell proliferation in Arabidopsis [38, 39]. A significantly reduced root length in miR396 overexpression lines was linked with a reduction of dividing cells number in root apical meristem of the model legume Medicago truncatula, which showed lower GRFs expression [40]. It has been reported that miR319 mediated TCP4 represses Arabidopsis cell proliferation partially through the direct positive regulation of miR396 [41]. On the other hand, miR319/TCP4 module regulates jasmonic acid biosynthesis, as showed by a recent report, suggesting that overexpression of miR319 in tomato reduced endogenous jasmonic acid level [42]. Recently, it has been revealed that jasmonic acid could enhance Al-induced root inhibition in Arabidopsis due to increased microtubule depolymerization, and this progress was regulated by ethylene [43]. In this study, osa-miR319a-3p was up regulated while ata-miR396a-5p and ata-miR396e-5p were down regulated in XZ29, showing the opposite expression patterns. Therefore, the similar regulatory module between miR319/TCP4 and miR396 might be applied in barley to detoxify Al. It can be concluded that miR319 mediated HvTCP4 was significantly down regulated in
XZ29 relative to that in Golden Promise, in order to alleviate $\mathrm{Al}$ induced root inhibition aggravated by jasmonic acid. Meanwhile, miR396 expression was also reduced in XZ29, leading to enhanced root cell proliferation.

\section{Ath-miR8175 regulating HvNIP1; 2 might act as Al transporter}

To cope with $\mathrm{Al}$ stress, rice has developed a transport system for $\mathrm{Al}$ sequestration into vacuoles, which is mediated by OsNart1 and OsALS1 [16, 17]. Members of aquaporin family, which mostly transported non-charged substrates, were involved in $\mathrm{Al}$ transport in some plants such as hydrangea $[20,21]$. In addition, a recent study reported that plasma membrane localized transporter AtNIP1; 2 was involved in $\mathrm{Al}$ uptake from root cell wall into symplasm, and root to shoot translocation in the form of Al-malate complex [44]. Compared with rice and Arabidopsis, barley is relatively more $\mathrm{Al}$ sensitive, and internal $\mathrm{Al}$ detoxification mechanisms including $\mathrm{Al}$ transporters are hardly known. In this study, the gene $H v N I P 1 ; 2$, negatively regulated by ath-miR8175, was significantly up-regulated in both XZ29 and Golden Promise. However, the expression of ath-miR8175 was greatly increased in XZ29, thus potential upstream genes might differ in XZ29 and lead to enhancement of HvNIP1; 2, like the relation between OsART1 and OsNart1 [16]. Belonging to nodulin-26 like intrinsic protein (NIP) subfamily of aquaporin family, HvNIP1; 2 is homologous with AtNIP1; 2. Based on these facts, it may be assumed that $H v N I P 1 ; 2$ might act as an $\mathrm{Al}$ transporter to facilitate $\mathrm{Al}$ complex uptake from root cell wall into cytosol, but does not participate in $\mathrm{Al}$ translocation from root to shoot.

\section{Novel miRNAs exclusively expressing in Tibetan wild barley XZ29}

In the current study, two novel miRNAs, PC-miR1 and PC-miR2 were exclusively detected in XZ29, and not in Golden Promise. The miRNA PC-miR2 showed higher expression under $\mathrm{Al}$ stress in XZ29. This novel miRNA dampened the expression of target gene HORVU1Hr1G074900.1, which encoded BZIP (basic leucine zipper) transcription factor. In common bean, $\mathrm{Al}$ stress suppressed the expression of transcription factors such as BZIP and $M Y B$ in drought-induced ABA pathway [45]. However, the relation between $\mathrm{Al}$ stress and BZIP is hardly known. In addition, the target gene HORVU4Hr1G042240.2 of another novel miRNA PC-miR1, which encoded hexosyltransferase, might be associated with pectin biosynthesis in cell wall. It was well documented that pectin was related to Al tolerance [13]. Higher PME activity in an $\mathrm{Al}$-sensitive rice cultivar was linked with greater proportion of demethylated pectin [13]. Similarly, Al sensitive maize showed low-methylated pectin [46]. Based on these findings, it might be assumed 
that Golden Promise should have higher cell wall pectin content because of no regulation by miRNAs PC-miR1. More demathylated pectin might be produced due to higher PME activity, resulting in more $\mathrm{Al}$ ions binding to cell wall in Golden Promise. As a result, Golden Promise had higher root $\mathrm{Al}$ concentration than XZ29 (Fig. 1d). In conclusion, the exclusively expressed novel miRNA PC-miR1 could detoxify $\mathrm{Al}$ stress through altering cell wall component, but its precise roles need to be explored in further studies.

In addition to the miRNAs discussed above, some other miRNAs such as osa-miR444a-3p.2 and ata-miR1432-5p could be also involved in $\mathrm{Al}$ stress responses. $\mathrm{Al}$ stress reduced osa-miR444a-3p accumulation in XZ29 and enhanced the expression of target gene HORVU2Hr1G080490.1 encoding MADS-box transcription factor 27 in both genotypes, with XZ29 being more affected than Golden Promise. It was reported that miR444a overexpression affected rice lateral, primary and adventitious root growth through mediating nitrate signaling pathway [47]. In this study, we found HORVU1Hr1G094160.1, which encoded calmodulin like 43 (CML43) proteins, was greatly up-regulated in Golden Promise, but remained little change in XZ29. However, the physiological roles of most CMLs are still unclear, indicating the potential significance in deciphering their functions.

Based on analysis of miRNAs responding to $\mathrm{Al}$ stress, we developed a model to reveal Al tolerant strategies in XZ29 (Fig. 5). miR160 and miR393 participating in auxin signaling pathway, PC-miR1 being involved in cell wall pectin biosynthesis and miR319/TCP4 module as well as miR396 taking part in cell proliferation, play important roles in regulation of $\mathrm{Al}$-induced root inhibition. The gene $H v N I P 1 ; 2$ might be responsible for $\mathrm{Al}$ transport. All these findings provide a framework for understanding the roles of miRNAs in the novel mechanism of $\mathrm{Al}$ tolerance in the Tibetan wild barley.

\section{Conclusions}

The gene HvAACT1 and organic acids secretion are not responsible for $\mathrm{Al}$ tolerance in the Tibetan wild barley accession XZ29. Small RNA sequencing is an efficient way to detect miRNAs involved in biotic and abiotic stress. In this study, 50 miRNAs were responsive to $\mathrm{Al}$ stress in Golden Promise and XZ29. Among them, 17 miRNAs were up-regulated and 24 miRNAs were down-regulated in XZ29. These miRNAs play important roles in Al tolerance in the Tibetan wild barley.

\section{Methods}

\section{Plant materials and culture conditions}

Tibetan wild barley accession XZ29 and a cultivated barley Golden Promise were used to compare Al tolerance, expression level of $H v A A C T 1$ and secretion of organic acids. An Al-tolerant cultivar Dayton was used as a reference genotype. The seeds of XZ29 were obtained from Huazhong Agricultral University, China; and the seeds of cultivars Golden Promise and Dayton were from University of Tasmania, Australia. Barley seeds were disinfected with $3 \% \mathrm{H}_{2} \mathrm{O}_{2}$ for 20 min and then soaked in deionized water for $4 \mathrm{~h}$ at $22{ }^{\circ} \mathrm{C}$. Finally, seeds were germinated hydroponically on surface of 1.1-L plastic pots filled with aerated $0.5 \mathrm{mM} \mathrm{CaCl}$ solution and placed in a growth chamber $\left(22 / 18{ }^{\circ} \mathrm{C}\right.$, day/night) at dark environment, then two days later supplied light with $250 \mu \mathrm{mol} \mathrm{m}^{-2} \mathrm{~s}^{-1}$.

XZ29 and Golden Promise were used to generate miRNA data. Seeds of two genotypes were germinated on moist filter papers in a growth chamber under dark environment. After 7 days germination, seedlings were transferred into 5 -L plastic containers with aerated one-fifth Hoagland solution and renewed every 3 days.

\section{Measurement of root elongation and Al concentration}

Three-day-old seedlings prepared as described above were exposed to $1 \mathrm{mM}$ aerated $\mathrm{CaCl}_{2}$ solution containing 0, 5 and $10 \mu \mathrm{M} \mathrm{Al}$ at $\mathrm{pH} 4.5$. The solution was renewed daily. After treatment for 9 days, root elongation was measured as the length of the longest root. The relative root elongation was calculated as the formula: the longest root length with $\mathrm{Al}$ treatment/the longest root length without $\mathrm{Al}$ treatment $\times 100 \%$. The whole roots were harvested and washed three times with $5 \mathrm{mM} \mathrm{CaCl}_{2}$ solution. Samples were dried in an oven at $70{ }^{\circ} \mathrm{C}$ for 2 days and then digested completely in $\mathrm{HNO}_{3}$ solution using a microwave digestion instrument (Multiwave 3000, Anton Paar $\mathrm{GmbH}$, Australia). The concentration of $\mathrm{Al}$ in the digested solution was determined by inductively coupled plasma optical emission spectrometer (ICP-OES) (iCAP 6000 series, Thermo Fisher scientific, USA).

\section{Identification of the 1-kb insertion in the upstream region of HvAACT1}

DNA was extracted from shoots according to the instructions of MiniBEST Universal Genomic DNA Extraction Kit Ver.5.0 (TaKaRa, Japan). To examine the presence of the insertion in three barley genotypes, upstream fragments of the HvAACT1 encoding region were amplified by PCR using KOD-FX (Toyobo, Japan) from the genomic DNA. PCR primers (5'-GGTCCAACACTCTACCCTT CCTT-3'and5'-GGTGCGAGTTGCCCCTAGCTATTAC AGA-3') were used as showed by Fujii et al. [23]. The PCR products were separated by electrophoresis of $120 \mathrm{~V}$ running for $30 \mathrm{~min}$ on a $1 \%$ agarose gel using $1 \times \mathrm{TAE}$ buffer and stained with $4 \mathrm{~S}$ green plus nucleic acid stain (Sangon Biotech, Shanghai, China).

\section{Determination of $H v A A C T 1$ expression}

To compare the HvAACT1 expression level in XZ29, Golden Promise and Dayton, four-day-old seedlings were 


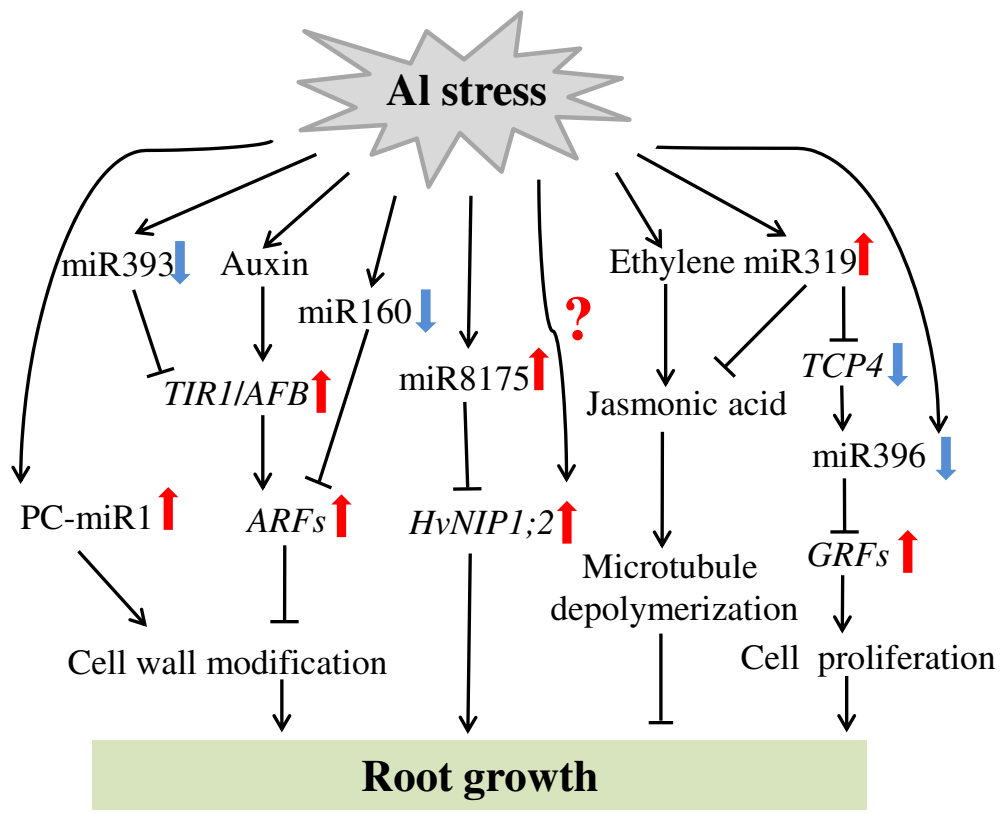

Fig. 5 A model presenting Al responses in XZ29. Down regulation of miR160 and miR393, accumulation of jasmonic acid cause root growth inhibition. To alleviate the inhibition, the expression of miR319 and miR396 is significantly changed, resulting in acceleration of cell proliferation. On the other hand, the specifically expressed miRNA PC-miR1 in XZ29 might affect cell wall component through influencing pectin biosynthesis, leading to less Al ions binding to cell wall. Al transporters facilitate Al from cell wall into cytosol and then Al is stored in nontoxic forms

exposed to $1 \mathrm{mM}$ aerated $\mathrm{CaCl}_{2}$ solution containing $5 \mu \mathrm{M}$ $\mathrm{Al}$ at $\mathrm{pH} 4.5$ for $6 \mathrm{~h}$. Two root segments $(0-1 \mathrm{~cm}$ and $1-$ $2 \mathrm{~cm}$ from tips) were sampled and frozen immediately in liquid nitrogen, then stored at $-80{ }^{\circ} \mathrm{C}$ before use. RNA was extracted by MiniBEST Universal RNA Extraction Kit (TaKaRa, Japan) according to instructions from manufacture. First strand cDNA was synthesized using Reverse Transcriptase Kit (TaKaRa, Japan). The qRT-PCR reaction consisting of SYBR Green Supermix (Bio-Rad, America) was conducted on real-time PCR System (LightCycler $480^{\circ} \mathrm{II}, 96$, Roche, Switzerland). Primers of HvAACT1 (5'-GTTCGCCAAGAACGATCACA-3' and 5'-AGAG ACCAAGCACCACCGTC-3') were taken from fujii et al. [23]. Actin was used as an internal control by the $\Delta \Delta \mathrm{Ct}$ method and primers used for Actin were 5'-GACT CTGGTGATGGTGTCAGC-3' and 5'-GGCTGGAAG AGGACCTCAGG-3' taken from Furukawa et al. [8]. Expression data of $H v A A C T 1$ were normalized with those in the 1-2 cm root tips of Golden Promise.

\section{Measurement of organic acids secretion}

Root exudates were collected from four-day-old seedlings of three barley genotypes exposed to $1 \mathrm{mM}$ aerated $\mathrm{CaCl}_{2}$ solution containing $10 \mu \mathrm{M} \mathrm{Al}$ at $\mathrm{pH} 4.5$ for $6 \mathrm{~h}$. Obtained root exudates were passed through $5 \mathrm{~g}$ cation exchange resin (Amerlite IR-120H, Sigma) followed by $2 \mathrm{~g}$ anion exchange resin (Dowex $1 \times 8$ resin, 100-200 mesh, chloride form, Sigma). Organic acids retained in anion exchange resin were eluted immediately with $1 \mathrm{M}$
$\mathrm{HCl}$ and then the eluent was dried to powder using rotary evaporator at $40{ }^{\circ} \mathrm{C}$. The powder was dissolved in $2 \mathrm{ml}$ of distilled water and passed through a $0.2 \mu \mathrm{m}$ syringe filter. The concentration of organic acids was determined by ion chromotography (ICS 2000; Dionex).

\section{Small RNA and degradome library construction and sequencing}

XZ29 and Golden Promise were used for small RNA and degradome sequencing. After grown in one-fifth Hoagland solution for 12 days, these two genotypes were treated with $1 \mathrm{mM}$ aerated $\mathrm{CaCl}_{2}$ solution containing 0 or $10 \mu \mathrm{M}$ $\mathrm{Al}$ at $\mathrm{pH} 4.5$ for $24 \mathrm{~h}$. A total of eight root samples (two genotypes in control and Al-treated conditions with two replications) each consisting of three plants were harvested. In addition to construction of eight small RNA libraries, all remained samples were mixed well for RNA collection to establish one degradome library. Total RNA was extracted using Trizol reagent (Invitrogen, CA, USA). Approximately $1 \mu \mathrm{g}$ of total RNA was used to prepare small RNA library following the manufacture of TruSeq Small RNA Sample Prep Kits (Illumina San Diego, USA), while approximately $20 \mu \mathrm{g}$ of total RNA was used for degradome library construction according to the protocols described previously [48]. Then single-end sequencing (50 bp) were performed on an Illumina Hiseq2500 (Illumina, San Diego, USA) following protocols of the producer. The detailed information about sequencing quality was showed in Additional file 4: Table S2. 


\section{Prediction of miRNA and their targets}

The raw reads for small RNA sequencing were processed with the program ACGT101-miR (LC Sciences, USA) to remove adapters, junk reads, low-complexity sequences, mRNA (ftp://ftp.ensemblgenomes.org/pub/plants/release -36/fasta/hordeum_vulgare/cds/Hordeum_vulgare.Hv_IBS C_PGSB_v2.cds.all.fa.gz), repeats (V18.02; http://www.gir inst.org/repbase) and common non-coding RNA families including rRNA, tRNA, snRNA and snoRNA (version 11; http://rfam.janelia.org). Subsequently, the remaining clean unique sequences with the length of 18-25 nucleotides were mapped to miRBase (version 21; ftp://mirbase.org/ $\mathrm{pub} / \mathrm{mirb}$ ase/CURRENT/). Length variation at both 3' and 5 ' ends and two mismatches inside of the sequence were allowed in the alignment. The unique sequences mapping to barley and other plant mature miRNAs in miRBase were identified as the known miRNAs. The remained unique sequences mapping to the arm of the known precursor hairpin were considered to be new members of known miRNAs. The mapped pre-miRNAs were further compared to barley genome (http://plants.ensembl.org/ Hordeumvulgare/Info/Index) to determine genomic locations. Finally, the unmapped sequences were blasted against barley genome, and then the flank $120 \mathrm{nt}$ sequences were extracted to predict secondary structures using RNAfold software (http://rna.tbi.univie.ac.at/cgi -bin/RNAfold.cgi). The criteria were adjusted as follows: (1) number of nucleotides in one bulge in stem is $\leq 12$, (2) number of base pairs in the stem region of the predicted hairpin is $\geq 16$, (3) the free energy for miRNA precursor should be $\leq-15 \mathrm{kCal} / \mathrm{mol}$, (4) length of hairpin is larger than 50 but less than $200 \mathrm{nt}$, (5) number of nucleotides in one bulge in mature region is $\leq 4$, (6) number of biased errors in one bulge in mature region should be $\leq 2$ (7) number of biased bulges in mature region is $\leq 2$, (8) number of errors in mature region is $\leq 4$, (9) number of base pairs in the mature region of the predicted hairpin is $\geq 12$, (10) percent of mature in stem is $\geq 80$. All remaining sequences meeting these parameters were considered to be potential candidate miRNAs (PC-miRNAs). The raw reads for miRNAs were normalized by the global normalization procedures [49].

The program TargetFinder was used to identify miRNA binding sites in terms of bioinformatics analysis. In addition, degradome library was constructed to further predict the target genes of miRNAs. Raw sequencing reads were filtered by Illumina's Pipeline software (version 1.5) and then CleaveLand3.0 was used for sequencing data analysis. Finally, degradome reads were mapped to barley mRNA database. All function annotation of target genes was taken from barley CDS database in IPK (http://webblast.ipk-gatersle ben.de/barley_ibsc/downloads/160517_Hv_IBSC_PGSB_r1_ CDS_HighConf_REPR_annotation.fasta.gz).

\section{Identification of miRNAs responsive to Al stress}

miRNAs responsive to $\mathrm{Al}$ stress should meet the rules as showed below. (1) One of normalized reads was larger than 100 from two genotypes in Al-treated or control conditions. (2) MFEI (minimal folding free energy index) of newly found miRNAs was larger than 0.85. (3) The fold change between $\mathrm{Al}$ treatment and control normalized reads in Golden Promise and XZ29 was calculated as the formula: fold change $=\log 2$ (Al reads/control reads). miRNAs were significantly up-regulated with fold change $\geq 0.5$, down-regulated with fold change $\leq-0.5$, unchanged with $\mid$ fold change $\mid<0.5$.

\section{Transcript analysis of miRNA target genes}

To validate the small RNA sequencing data, four randomly selected target genes from miRNAs responsive to $\mathrm{Al}$ stress were used to perform qRT-PCR analysis. RNA samples used for CDNA synthesis were the same as those for small RNA library construction. All the next procedures were followed as those described in determination of HVAACT1 expression. The primers of HORVU2Hr 1G080490.1 (5'-TCATCGGCAGTTGATGGGAC-3' and 5'-GGTGGACAAGACTCCCCTTG-3'), HORVU1Hr1G0 94160.1 (5'-GGGTGTGAAGGACTTGGTGT-3' and 5'-C TCATCGAAGGCACGGATCA-3'), HORVU5Hr1G1034 00.1 (5'-GCTCAAGCCGGAGACTACAG-3' and 5'-CTG CTCGTACAGGAAGGGAG-3') and HORVU5Hr1G085 710.3 (5'-CCCAATTAGTGGCGCTGTTG-3' and 5'-AG CTCATCCTTGCACTTCGT-3') were used and Actin was taken as an internal control by the $\Delta \Delta \mathrm{Ct}$ method. Every sample was carried out with two technical replicates.

\section{Additional files}

Additional file1: Figure S1. The difference in root elongation of three genotypes under Al stress. Three-day-old seedlings were exposed to Al for 9 days. The root elongation were measured. Data are means +SD of six biological replicates and means labeled with different letters are significantly different at $p<0.05$ by Tukey' test. (PDF 225 kb)

Additional file2: Figure S2. Length distribution of small RNAs in control and Al-treated roots of Golden Promise and XZ29. (PDF 225 kb)

Additional file3: Table S1. Detailed information of total detected miRNAs in Golden Promise and XZ29. (XLSX 60 kb)

Additional file4: Table S2. Detailed information of miRNA libraries sequencing. (XLSX $9 \mathrm{~kb}$ )

\footnotetext{
Abbreviations

ABC: ATP-binding cassette; AFB: auxin-signaling F-box; ALMT: Al-activated malate transporter; ALS1: Al-sensitive 1; ARFs: auxin response factors; ART1: Al resistance transcription factor 1; BZIP: basic leucine zipper; CML43: calmodulin like 43; GWAS: Genome-wide association study; HvAACT1: Al-activated citrate transporter 1; MATE: multidrug and toxic compound extrusion; MFEl: minimal folding free energy index; miRNAs: microRNAs; NAC: NAM, ATAF1/2 and CUC2; Nart1: Nramp aluminum transporter 1; NIP: nodulin-26 like intrinsic protein; PALT1: plasma membrane aluminum transporter 1; PMEls: pectin methylesterase inhibitors; PMEs: pectin methylesterases; SPL: Squamosa Promoter Binding-Like; STAR1: sensitive to Al rhizotoxicity1; TIR1: transport inhibitor response; VALT: vacuolar aluminum transporter; XTH3: xyloglucan endotransglucosylase/hydrolase
} 


\section{Acknowledgements}

We are deeply grateful to Prof. Dongfa Sun (Huazhong Agricultral University, China) for providing seeds of Tibetan wild barley XZ29 and Prof. Meixue Zhou (University of Tasmania, Australia) for providing seeds of cultivars Golden Promise and Dayton.

\section{Funding}

This study was supported by the National Natural Science Foundation of China (31620103912), the China Agriculture Research System (CARS-05), the Jiangsu Collaborative Innovation Center for Modern Crop Production (JCIC-MCP) and the Fundamental Research Funds for the Central Universities.

\section{Availability of data and materials}

The raw reads of this study were deposited in the SRA database (http:// www.ncbi.nlm.nih.gov/sra/) at NCBI with BioProject accession number PRJNA481620 and SRA accession number SRP154492 (Small RNA sequencing: SRR7543962-SRR7543969; Degradome sequencing: SRR7543970).

\section{Authors' contributions}

LYW, DZW and GPZ conceived and designed the research. LYW, JHY, QFS and LH performed the experiments and data analysis. LYW and DZW wrote the article. LH, DZW and GPZ revised the manuscript. All authors read and approved the manuscript.

\section{Ethics approval and consent to participate} Not applicable

\section{Consent for publication}

Not applicable.

\section{Competing interests}

The authors declare that they have no competing interests.

\section{Publisher's Note}

Springer Nature remains neutral with regard to jurisdictional claims in published maps and institutional affiliations.

\section{Received: 12 March 2018 Accepted: 23 July 2018}

\section{Published online: 31 July 2018}

\section{References}

1. Panda SK, Baluška F. Aluminum stress adaptation in plants. Switzerland: Springer International Publishing; 2015.

2. von Uexküll HR, Mutert E. Global extent, development and economic impact of acid soils. Plant Soil. 1995:171(1):1-15.

3. Kochian LV, Hoekenga OA, Piñeros MA. How do crop plants tolerate acid soils? Mechanisms of aluminum tolerance and phosphorous efficiency. Annu Rev Plant Biol. 2004:55:459-93.

4. Ma JF. Role of organic acids in detoxification of aluminum in higher plants. Plant Cell Physiol. 2000;41(4):383-90.

5. Delhaize M, Gruber BD, Ryan PR. The roles of organic anion permeases in aluminium resistance and mineral nutrition. FEBS Lett. 2007:581(12):2255-62.

6. Ryan PR, Tyerman SD, Sasaki T, Furuichi T, Yamamoto Y, Zhang WH, et al The identification of aluminium-resistance genes provides opportunities for enhancing crop production on acid soils. J Exp Bot. 2011;62(1):9-20.

7. Sasaki T, Yamamoto Y, Ezaki B, Katsuhara M, Ahn SJ, Ryan PR, et al. A wheat gene encoding an aluminum-activated malate transporter. Plant J. 2004; 37(5):645-53.

8. Furukawa J, Yamaji N, Wang H, Mitani N, Murata Y, Sato K, et al. An aluminum-activated citrate transporter in barley. Plant Cell Physiol. 2007; 48(8):1081-91

9. Yokosho K, Yamaji N, Ma JF. An Al-inducible mate gene is involved in external detoxification of Al in rice. Plant J. 2011:68(6):1061-9.

10. Kochian LV, Piñeros MA, Liu JP, Magalhaes JV. Plant adaptation to acid soils: the molecular basis for crop aluminum resistance. Annu Rev Plant Biol. 2015;66:571-98.

11. Ma JF. Syndrome of aluminum toxicity and diversity of aluminum resistance in higher plants. Int Rev Cytol. 2007;264:225-52.

12. Micheli F. Pectin methylesterases: cell wall enzymes with important roles in plant physiology. Trends Plant Sci. 2001;6(9):414-9.
13. Yang JL, Li YY, Zhang YJ, Zhang SS, Wu YR, Wu P, et al. Cell wall polysaccharides are specifically involved in the exclusion of aluminum from the rice root apex. Plant Physiol. 2008;146(2):602-11.

14. Yang XY, Zeng ZH, Yan JY, Fan W, Bian HW, Zhu MY, et al. Association of specific pectin methylesterases with Al-induced root elongation inhibition in rice. Physiol Plant. 2013;148(4):502-11.

15. Huang CF, Yamaji N, Mitani N, Yano M, Nagamura Y, Ma JF. A bacterial-type $A B C$ transporter is involved in aluminum tolerance in rice. Plant Cell. 2009: 21(2):655-67.

16. Xia JX, Yamaji N, Kasai T, Ma JF. Plasma membrane-localized transporter for aluminum in rice. Proc Natl Acad Sci U S A. 2010;107(43):18381-5.

17. Huang CF, Yamaji N, Chen ZC, Ma JF. A tonoplast-localized half-size ABC transporter is required for internal detoxification of aluminum in rice. Plant J. 2012;69(5):857-67.

18. Ma JF, Hiradate S. Form of aluminium for uptake and translocation in buckwheat (Fagopyrum esculentum Moench). Planta. 2000;211(3):355-60.

19. Ma JF, Hiradate S, Nomoto K, Iwashita T, Matsumoto H. Internal detoxification mechanism of Al in hydrangea (identification of Al form in the leaves). Plant Physiol. 1997:113(4):1033-9.

20. Negishi T, Oshima K, Hattori M, Kanai M, Mano S, Nishimura M, et al. Tonoplast- and plasma membrane-localized aquaporin-family transporters in blue hydrangea sepals of aluminum hyperaccumulating plant. PLoS One. 2012;7(8):e43189.

21. Negishi T, Oshima K, Hattori M, Yoshida K. Plasma membrane-localized Altransporter from blue hydrangea sepals is a member of the anion permease family. Genes Cells. 2013;18(5):341-52.

22. Yamaji N, Huang CF, Nagao S, Yano M, Sato Y, Nagamura $Y$, et al. A zinc finger transcription factor ART1 regulates multiple genes implicated in aluminum tolerance in rice. Plant Cell. 2009;21(10):3339-49.

23. Fujii M, Yokosho K, Yamaji N, Saisho D, Yamane M, Takahashi H, et al. Acquisition of aluminium tolerance by modification of a single gene in barley. Nat Commun. 2012;3(2):713.

24. Cai SG. Studies on Mechanisms of Aluminum toxicity tolerance in Tibetan wild barley (PhD thesis). China: Zhejiang University; 2013.

25. Cai SG, Wu DZ, Jabeen Z, Huang YQ, Huang YC, Zhang GP. Genome-wide association analysis of aluminum tolerance in cultivated and Tibetan wild barley. PLoS One. 2013;8(7):e69776

26. Dai $F$, Nevo E, Wu DZ, Comadran J, Zhou M, Qiu L, et al. Tibet is one of the centers of domestication of cultivated barley. Proc Natl Acad Sci U S A. 2012;109(42):16969-73.

27. Sun GL. MicroRNAs and their diverse functions in plants. Plant Mol Biol. 2012:80(1):17-36.

28. Voinnet O. Origin, biogenesis, and activity of plant microRNAs. Cell. 2009; 136(4):669-87.

29. Miura K, Ikeda M, Matsubara A, Song XJ, Ito M, Asano K, et al. OsSPL14 promotes panicle branching and higher grain productivity in rice. Nat Genet. 2010:42(6):545-9.

30. Wang SK, Wu K, Yuan QB, Liu XY, Liu ZB, Lin XY, et al. Control of grain size, shape and quality by OSSPL16 in rice. Nat Genet. 2012:44(8):950-4.

31. Bhogale S, Mahajan AS, Natarajan B, Rajabhoj M, Thulasiram HV, Banerjee AK. MicroRNA156: a potential graft-transmissible microRNA that modulates plant architecture and tuberization in Solanum tuberosum ssp. andigena. Plant Physiol. 2014:164(2):1011-27.

32. Chen L, Wang TZ, Zhao MG, Tian QY, Zhang WH. Identification of aluminum-responsive microRNAs in Medicago truncatula by genome-wide high-throughput sequencing. Planta. 2012;235(2):375-86

33. Ding YF, Ye YY, Jiang ZH, Wang Y, Zhu C. MicroRNA390 is involved in cadmium tolerance and accumulation in rice. Front Plant Sci. 2016;7:235.

34. Kopittke PM, Moore KL, Lombi E, Gianoncelli A, Ferguson BJ, Blamey FPC, et al. Identification of the primary lesion of toxic aluminum in plant roots. Plant Physiol. 2015;167(4):1402-11.

35. Xia KF, Wang R, Ou XJ, Fang ZM, Tian CG, Duan J, et al. OsTIR1 and OsAFB2 downregulation via OsmiR393 overexpression leads to more tillers, early flowering and less tolerance to salt and drought in rice. PLoS One. 2012; 7(1):e30039.

36. Bai B, Bian HW, Zeng ZH, Hou N, Shi B, Wang JH, et al. miR393-mediated auxin signaling regulation is involved in root elongation inhibition in response to toxic aluminum stress in barley. Plant Cell Physiol. 2017:58(3): 426-39.

37. Yang ZB, Geng XY, He CM, Zhang F, Wang R, Horst WJ, et al. TAA1regulated local auxin biosynthesis in the root-apex transition zone mediates 
the aluminum-induced inhibition of root growth in Arabidopsis. Plant Cell. 2014;26(7):2889-904.

38. Pauwels L, Morreel K, De Witte E, Lammertyn F, Van Montagu M, Boerjan W, et al. Mapping methyl jasmonate-mediated transcriptional reprogramming of metabolism and cell cycle progression in cultured Arabidopsis cells. Proc Natl Acad Sci U S A. 2008;105(4):1380-5.

39. Rodriguez RE, Mecchia MA, Debernardi JM, Schommer C, Weigel D, Palatnik JF. Control of cell proliferation in Arabidopsis thaliana by microRNA miR396. Development. 2010;137(1):103-12.

40. Bazin J, Khan GA, Combier JP, Bustos-Sanmamed P, Debernardi JM, Rodriguez $\mathrm{R}$, et al. miR396 affects mycorrhization and root meristem activity in the legume Medicago truncatula. Plant J. 2013;74(6):920-34.

41. Schommer C, Debernardi JM, Bresso EG, Rodriguez RE, Palatnik JF. Repression of cell proliferation by miR319-regulated TCP4. Mol Plant. 2014; 7(10):1533-44.

42. Zhao WC, Li ZL, Fan JW, Hu CL, Yang R, Qi X, et al. Identification of jasmonic acid-associated microRNAs and characterization of the regulatory roles of the miR319/TCP4 module under root-knot nematode stress in tomato. J Exp Bot. 2015;66(15):4653-67.

43. Yang ZB, He CM, Ma YQ, Herde M, Ding ZJ. Jasmonic acid enhances Alinduced root-growth inhibition. Plant Physiol. 2016;173(2):1420-33.

44. Wang YQ, Li RH, Li D, Jia XM, Zhou DW, Li JY, et al. NIP1; 2 is a plasma membrane-localized transporter mediating aluminum uptake, translocation, and tolerance in Arabidopsis. Proc Natl Acad Sci U S A. 2017;114(19):5047-52.

45. Yang ZB, Eticha D, Albacete A, Rao IM, Roitsch T, Horst WJ. Physiological and molecular analysis of the interaction between aluminium toxicity and drought stress in common bean (Phaseolus vulgaris). J Exp Bot. 2012;63(8): 3109-25.

46. Eticha D, Stass A, Horst WJ. Cell-wall pectin and its degree of methylation in the maize root-apex: significance for genotypic differences in aluminium resistance. Plant Cell Environ. 2005;28(11):1410-20.

47. Yan YS, Wang HC, Hamera S, Chen XY, Fang RX. miR444a has multiple functions in the rice nitrate-signaling pathway. Plant J. 2014;78(1):44-55.

48. Ma ZR, Coruh C, Axtell MJ. Arabidopsis lyrata small RNAs: transient MIRNA and small interfering RNA loci within the Arabidopsis genus. Plant Cell. 2010; 22(4):1090-103.

49. Li X, Shahid MQ, Wu JW, Wang L, Liu XD, Lu YG. Comparative small RNA analysis of pollen development in autotetraploid and diploid rice. Int J Mol Sci. 2016:17(4):499.

Ready to submit your research? Choose BMC and benefit from:

- fast, convenient online submission

- thorough peer review by experienced researchers in your field

- rapid publication on acceptance

- support for research data, including large and complex data types

- gold Open Access which fosters wider collaboration and increased citations

- maximum visibility for your research: over $100 \mathrm{M}$ website views per year

At $\mathrm{BMC}$, research is always in progress.

Learn more biomedcentral.com/submissions 